\title{
Healthcare IT Utilization and Penetration among Physicians: Novel IT Solutions in Healthcare - Use and Acceptance in Hospitals
}

\author{
Ferdinand Vogt $^{a}$ Fritz Seidl $^{b, c}$ Giuseppe Santarpino ${ }^{a}$ \\ Martijn van Griensven ${ }^{c}$ Martin Emmert ${ }^{d}$ Guenther Edenharter ${ }^{e}$ \\ Dominik Pförringer ${ }^{b}$ \\ a Department of Cardiac Surgery, Klinikum Nürnberg, Paracelsus Medical University, \\ Nuremberg, Germany; ${ }^{b}$ Department of Trauma Surgery, Klinikum rechts der Isar, Technical \\ University of Munich, Munich, Germany; ${ }^{c}$ Department of Experimental Trauma Surgery, \\ Klinikum rechts der Isar, Technical University of Munich, Munich, Germany; ${ }^{d}$ Institute of \\ Management (IFM), School of Business and Economics, Friedrich Alexander University \\ Erlangen-Nuremberg, Nuremberg, Germany; ${ }^{e}$ Department of Anaesthesiology, Klinikum \\ rechts der Isar, Technical University of Munich, Munich, Germany
}

\section{Keywords}

Healthcare IT · Health monitoring · Information technology · Physicians · Demand - Outlook . Expectations - Data storage

\begin{abstract}
Background: Healthcare IT (HIT) increasingly gains public attention and clinical daily relevance. A growing number of patients and physicians increasingly relies on IT services to monitor and support well-being and recovery both in their private and professional environment. This is assumed to develop rapidly in the upcoming years. Objective: This study examines the current status of HIT, its use and penetration among physicians in hospitals and researches utilization as well as future expectations regarding HIT. Methods: Physicians in Germany, Austria and Switzerland were addressed via e-mail to answer a standardized Internet-based questionnaire consisting of 17 multiple-choice and 3 open text questions. Parameters were evaluated in 5 categories: general use, frequency, acceptance, IT needs and future expectations. Results: An overall 234 physicians (response rate $83.6 \%$ ) with a median age of 45 (range 2560 ) responded and filled out the entire online questionnaire. A significant correlation between parameters gender, age and level of training (resident, specialist, consultant etc.) was proven. The professional, medical employment of technology shows a strong correlation with age as well as level of training. Whereas increasing age among physicians is associated with a de-
\end{abstract}


Vogt et al.: Healthcare IT Utilization and Penetration among Physicians: Novel IT Solutions in Healthcare - Use and Acceptance in Hospitals

creasing level of application of HIT, a higher training level is accompanied by an increasing level of professional application of IT services and tools within the healthcare context. Routine employment of HIT is regarded as a necessary and positive standard. Most users assume the importance of HIT to strongly grow in the future in comparison to current use. A clear lack of trust towards data security and storage is recognized on both patient and physician sides. Needs are currently satisfied by employing privately acquired IT in the professional setup rather than the hospitals'. Future expectations from HIT show a clear demand for interoperability and exchangeability of data. Conclusions: The results display a clear gap between demand and expectations of IT for medical purposes. The rate of use of HIT applications generally correlates with age, gender as well as role within the hospital and type of employment within the healthcare sector. The current offering does not satisfy the needs of healthcare professionals.

(c) 2018 S. Karger AG, Basel

\section{Introduction}

\section{Present Status and Definition}

Healthcare IT (HIT) continuously grows in acceptance, recognition as well as daily clinical use, yet most physicians seem willing but unable to engage in the development of HIT [1]. Medical demand and physicians' opinion are rarely integrated during development of novel HIT solutions. At the same time a growing number of patients use HIT applications to monitor their health and physical conditions in case of various pathological entities [2-4] or to inform themselves about their treatment plan [5]. Approaches to improve the effectiveness and trustworthiness of tools for online communication between caregivers and patients have been scientifically examined [6-8], displaying a lack of connectivity and interoperability.

HIT is defined as, "the application of information processing involving both computer hardware and software that deals with the storage, retrieval, sharing, and use of health care information, data, and knowledge for communication and decision making" [9].

The underlying study aims to enhance the understanding of the current HIT utilization among physicians in German-speaking countries as well as their future expectations towards HIT. As seen in the US decisions on e-health use may have extensive technological, organizational, managerial as well as ethical implications [10]. In addition to that integration between current processes and modern technology in addition to healthcare, professionals' resistance against adoption poses the largest obstacles [11].

HIT in general aims to achieve the following:

- Improve healthcare quality, effectiveness, productivity and efficiency to improve processes

- Reduce medical errors and increase healthcare accuracy as well as procedural correctness

- Extend real-time communication of health information among healthcare professionals and thus expand access to affordable care

- Through all of the above reduce costs [12]

\section{Scientific Background}

The Health Information National Trends Survey portrays a tectonic shift in the ways patients consume health and medical information, with more patients looking for information online before talking to their physicians [13]. Chau and $\mathrm{Hu}$ [14] state that the mindset of physicians towards using IT solutions plays an important role for the adoption and application of these solutions. The relatively low application of IT in healthcare can among others 
Vogt et al.: Healthcare IT Utilization and Penetration among Physicians: Novel IT

Solutions in Healthcare - Use and Acceptance in Hospitals

be traced back to the formerly low acceptance among healthcare professionals [11], which is just beginning to change. Mobile HIT applications are regarded as helpful solutions for healthcare-specific problems such as integrated data acquisition or information exchange [15].

\section{Adoption and Future Expectations}

Earlier research on the application of HIT solutions in German-speaking countries renders several peculiarities apparent. A multicenter study performed in Cologne showed that a telemedical HIT application for the prevention of falls of elderly people reduced the risk of falls as expected by the investigators. However, it was also found that participants did not adhere to the suggested usage due to low feasibility, technical difficulties or low acceptance of the new technology [16]. Nevertheless, the same research group additionally discovered the new technology's potential for improving the effectiveness of individualized healthcare, while at the same time motivating and engaging users at comparably low cost [17]. Further research analyzing HIT use in 8 European countries (Denmark, Estonia, Germany, France, Italy, the Netherlands, Spain and the UK) found that use of new HIT applications is relatively limited due to skepticism on behalf of practitioners as well as patients. Therefore, studies show poor response rates despite offered compensation [18]. This allows for the potential conclusion of a high responsibility of physicians to become pioneers in the development of new technologies instead of blocking digital innovation [19]. Effective on May 25, 2018, the European General Data Protection Regulation (GDPR) will be enforceable. This will on the one hand give EU citizens and residents more control over their own data. On the other hand, innovative mandatory standards will influence access to data and business of international companies.

\section{Perspective of Our Research}

Physicians have started adopting HIT, but little are they involved in its development. The study at hand explicitly addresses physicians' needs and evaluates the current level of HIT applications among healthcare professionals as well as their future expectations from this technology. A profound understanding of current and future needs is key to future success and subsequent adoption of innovation.

In detail, the logical primary research question (RQ) of this study is:

RQ1: What is the current use of HIT in the professional setup (also regarding medical specialization) and which future importance do they expect?

Additionally, the study at hand investigates the following three secondary RQs:

RQ2: How is HIT currently perceived by hospital physicians?

RQ3: Will the importance of HIT for hospital physicians grow in the future?

RQ4: What do physicians expect from the use of HIT in regard to the interaction with their patients?

\section{Materials and Methods}

For the underlying study, a standard questionnaire was developed, tested and subsequently set up using Google Drive ${ }^{\circledR}$ technology. The questionnaire was generally structured in forms of current use, future use and expectations, needs and demands and statistical details.

The questionnaire was delivered to 280 physicians within German, Austrian and Swiss university, public and private hospitals via e-mail. Data were collected over the course of 12 weeks, achieving a total response rate of $83.6 \%(n=234)$. Before delivering the questionnaire, the set of questions was pilot-tested with 12 physicians within their own hospital departments.

The questionnaire consists of an overall of 20 questions (15 HIT-related specific and 5 personal questions regarding the field of specialization, age, geography, gender and type of employment) (see Appendix). 
Vogt et al.: Healthcare IT Utilization and Penetration among Physicians: Novel IT Solutions in Healthcare - Use and Acceptance in Hospitals

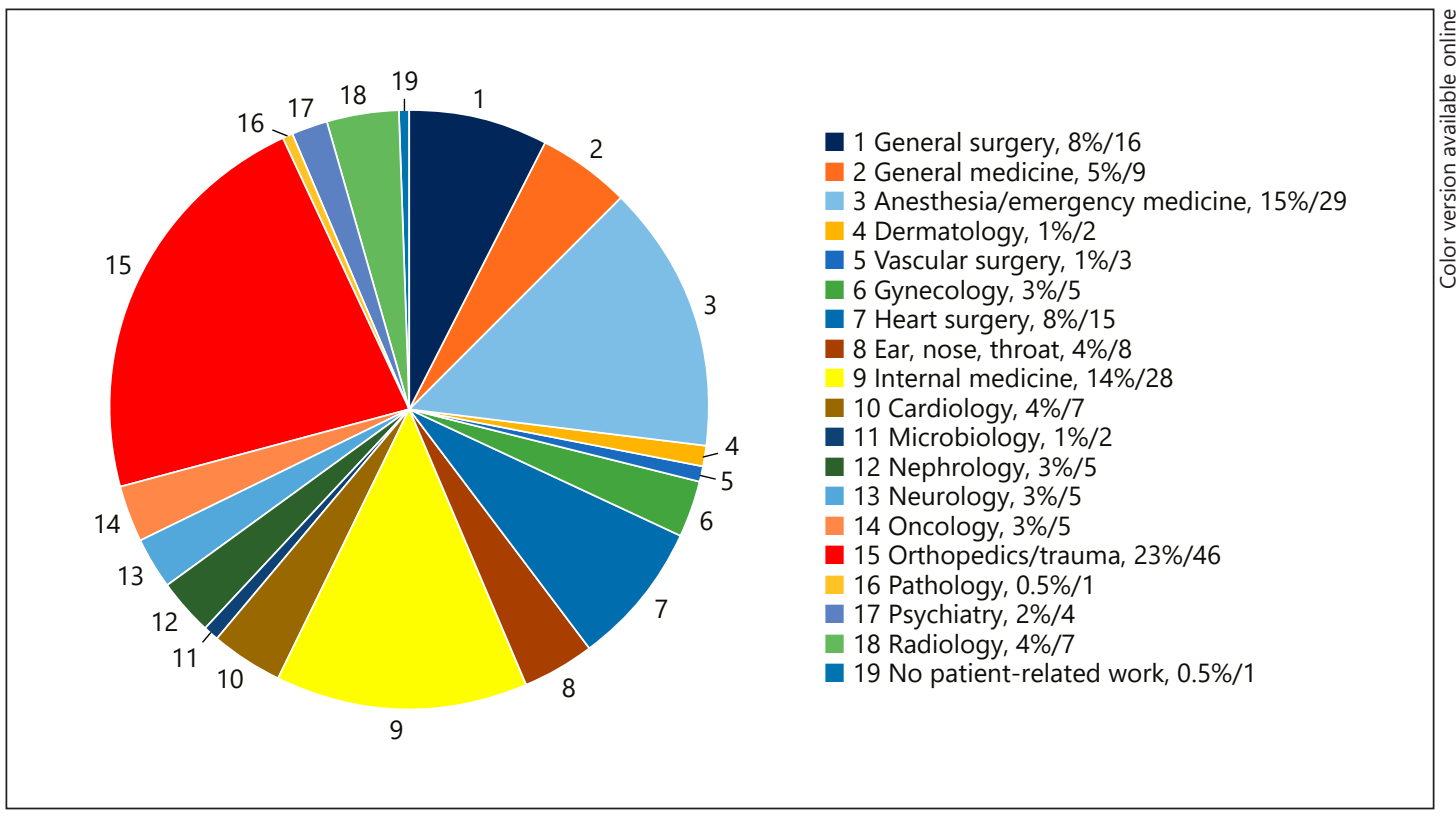

Fig. 1. Distribution of responders to the questionnaire among medical special fields (given as percentages/ absolute numbers).

"HIT" was explained at the beginning of the survey and defined as follows: "Healthcare IT = information technology, which facilitates the detection, management and exchange of information between patients, physicians and professional service providers within the health system".

The questionnaire was distributed via e-mail to hospital managements to reach out to relevant groups of physicians. An overall of 234 physicians completely answered the questionnaire between June and September 2015. Furthermore, all participants consented to the statistical and scientific evaluation of the anonymously generated data.

The above-mentioned 20 questions were split into 17 multiple-choice and 3 open text questions. In the multiple-choice questions, we chose a 4-point Likert scale, as uneven scales tend to produce too many "undecided" replies in the center. The scales were labeled distinctly (e.g. $1=$ never; 2 = rarely; $3=$ often; 4 = regularly) to improve comparability between the different responders.

To allow for valid comparisons between questions, the answers were pooled in 2 groups each. Answers with a value of 1 and 2 were defined as "seldom" and those with a value of 3 and 4 as "often". These qualitative statements were compared for two entities using Fisher's exact test. This statistical test was selected to generate reliable results given a limited number of responders in each subgroup. The comparison relating to the responding physicians' field of specialization was conducted using one-way analysis of variance, followed by a post hoc Tukey test to evaluate differences between the groups. Responder groups accounting for a share of $5 \%$ or higher of total responders were taken into account for comparison. For the questions about the assessment of present and future impact of HIT, plain descriptive analysis was performed to gain a quantitative statement. A $p$ value of less than 0.05 was labeled as statistically significant in both statistical analyses. GraphPad Prism ${ }^{\circledR}$ Version 5.01 was used for the statistical evaluation (GraphPad Software, San Diego, CA, USA).

\section{Results}

The chronological answer frequency followed an almost typical Bell curve, with a rather slow onset, relatively moderate rise, a short peak and an equivalently fading decrease. After 12 weeks, the survey was closed with a total response rate of $83 \%$. 
Fig. 2. Fields of application of HIT among physicians: professional in hospital or privately; values correspond to 1 = never, 2 = rarely, 3 = often, 4 = regularly. ${ }^{* * * *} p<$ $0.0001-\mathrm{RQ} 1$.

Vogt et al.: Healthcare IT Utilization and Penetration among Physicians: Novel IT Solutions in Healthcare - Use and Acceptance in Hospitals

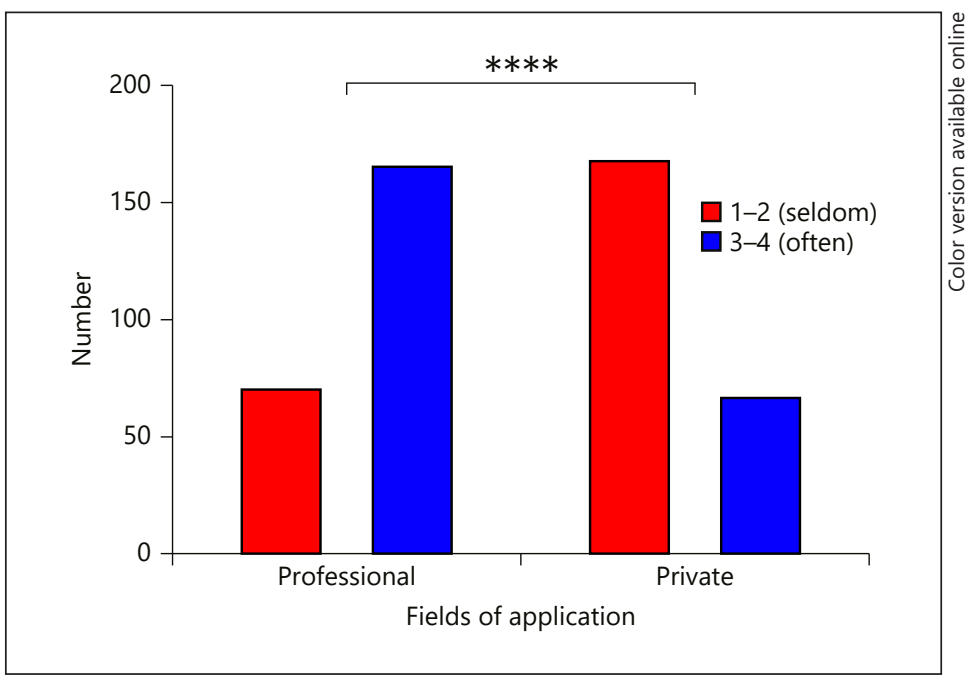

Partial answers were disregarded, only $100 \%$ filled questionnaires were taken into consideration yielding a total of 234 respondents of which $100 \%$ agreed on the use of their given answers for statistic and scientific evaluation.

\section{General Results}

Before focusing on the answers of our actual primary and secondary RQs as described in the introduction of the paper, the following paragraphs present some general results that provide information about the study demographics.

A desirable variety of physicians answered the survey. The largest fraction with $23 \%$ of all answers stems from orthopedics and trauma, followed by anesthetists (15\%) and internal medicine $(14 \%)$ as seen in Figure 1.

$70 \%$ of respondents were male, $30 \%$ female. With regard to degree of specialization, responses came from a relatively senior population. 31.3\% were assistants in training, $27.3 \%$ had already been examined for their specialization, $27.8 \%$ were consultants and $13.7 \%$ chiefs or department directors.

$85.6 \%$ of our responses stem from hospital physicians, $14.4 \%$ from those active in private practice. The largest proportion (34.9\%) of respondents stems from the age group of 45-60, with $9.2 \%$ older than that.

$36.8 \%$ of respondents stated to never use any form of HIT services.

The open text answers varied in length from 2 words up to 17 lines. The range of answers provided by the responders includes a broad variety of statements, some of which could not be interpreted unambiguously rendering a serious scientific interpretation impossible. Answers falling under this category were not taken into consideration for scientific evaluation.

Results Regarding the Primary Research Question (RQ1)

The following paragraphs focus on the study's primary research question: What is the current use of HIT in the professional setup (also regarding medical specialization) and which future importance do you expect?

$47.4 \%$ of physicians declared to frequently use their private smartphone for professional tasks during ward rounds or when treating patients. $12.5 \%$ are being offered some sort of a handheld or mobile device by their hospital. Physicians utilizing medical online offerings do 
Fig. 3. Comparison of professional HIT use between specializations; values correspond to $1=$ never, 2 = rarely, 3 = often, $4=$ regularly; bars are displayed as means \pm SEM. ${ }^{* *} p<0.01-$ RQ 1 .

Vogt et al.: Healthcare IT Utilization and Penetration among Physicians: Novel IT Solutions in Healthcare - Use and Acceptance in Hospitals

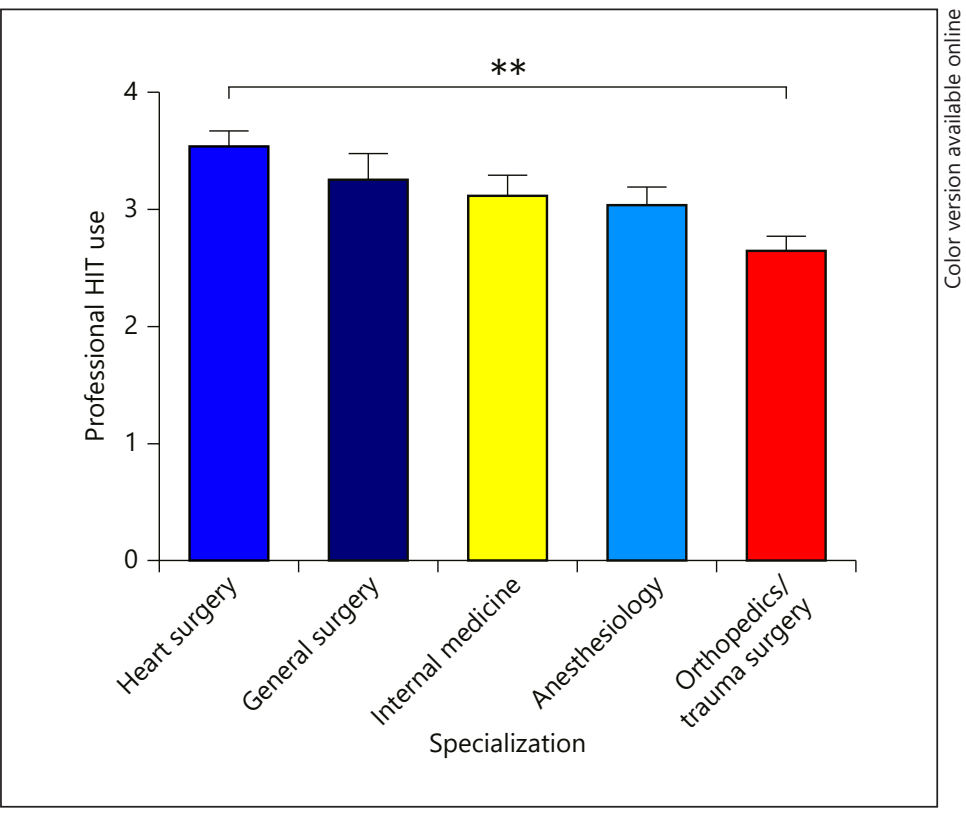

Fig. 4. Remote access $(n)$ of online patient data by medical professionals - RQ 1.

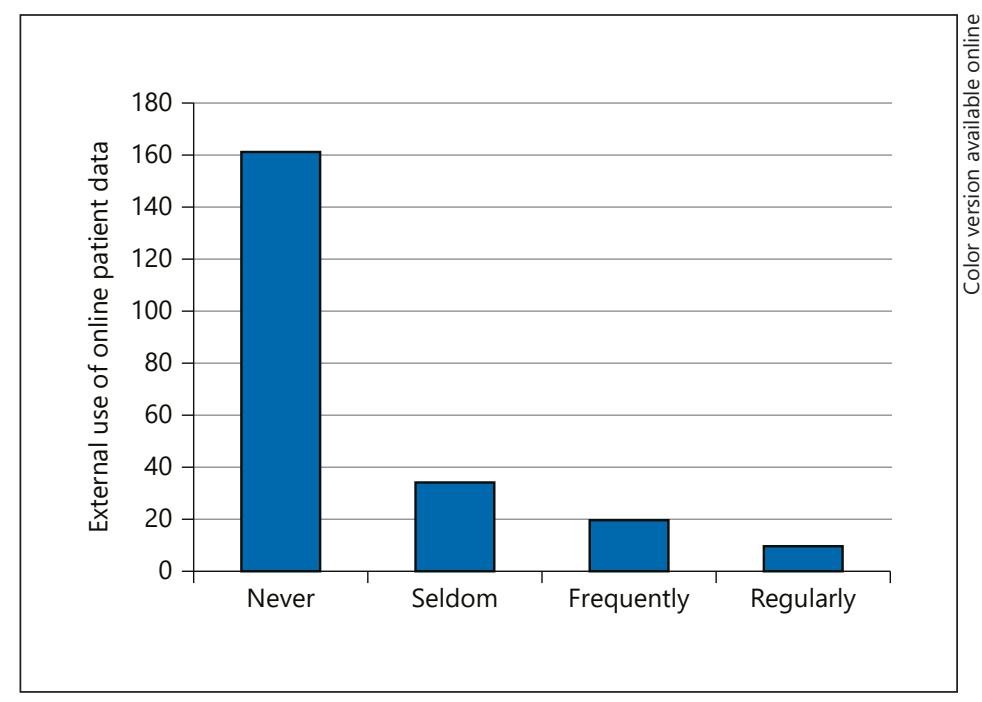

so more frequently in professional routine than privately $(p<0.001)$. Figure 2 shows that medical professionals make significantly more use of HIT while being in their professional surroundings than using IT at home.

With regard to physicians' field of specialization heart surgeons use HIT tools more frequently than their colleagues from other specializations. The variance between professional usage of HIT applications between heart surgeons and trauma surgeons is even highly statistically significant (with a mean difference of 0.9 ), while the other results show a trend towards increased usage in heart surgery over the other disciplines. The results are plotted in Figure 3.

Only 2 physicians $(0.9 \%)$ store their own medical records in a web-based tool such as Microsoft Health Vault or comparable systems. Respondents stated that $87.2 \%$ of their patients store no data at all within online-based platforms. 
Fig. 5. Use of direct appointments versus appointments via electronic calendars. ${ }^{* * * *} p<0.0001-\mathrm{RQ} 1$.

\begin{tabular}{l|l}
\hline DOI: $10.1159 / 000490241$ & $\begin{array}{l}\text { c } 2018 \text { S. Karger AG, Basel } \\
\text { www.karger.com/esr }\end{array}$ \\
\hline
\end{tabular}

Vogt et al.: Healthcare IT Utilization and Penetration among Physicians: Novel IT Solutions in Healthcare - Use and Acceptance in Hospitals

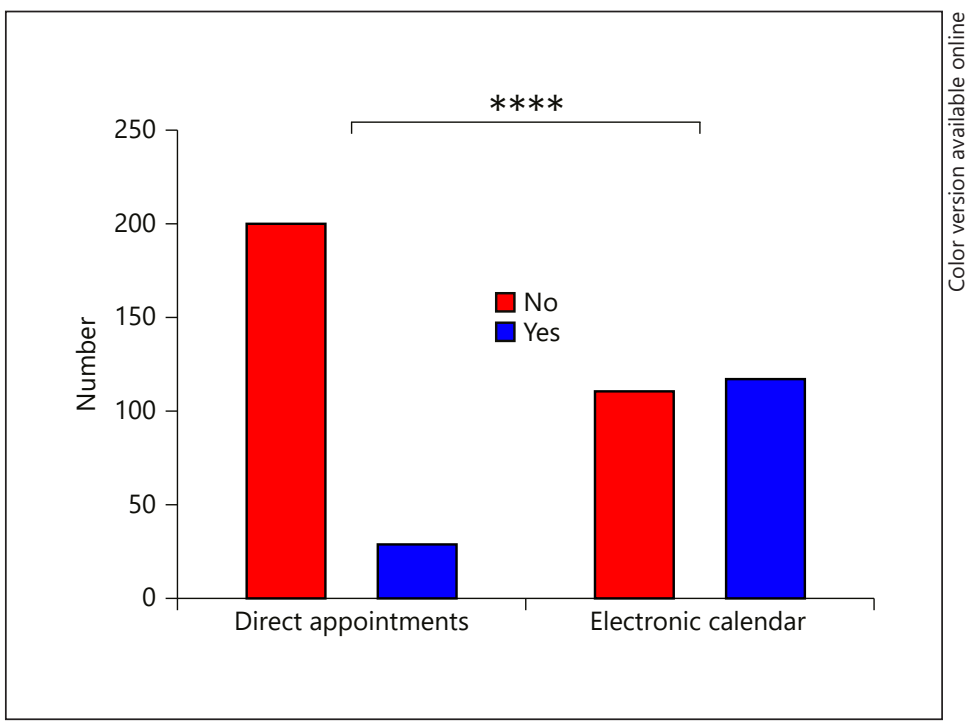

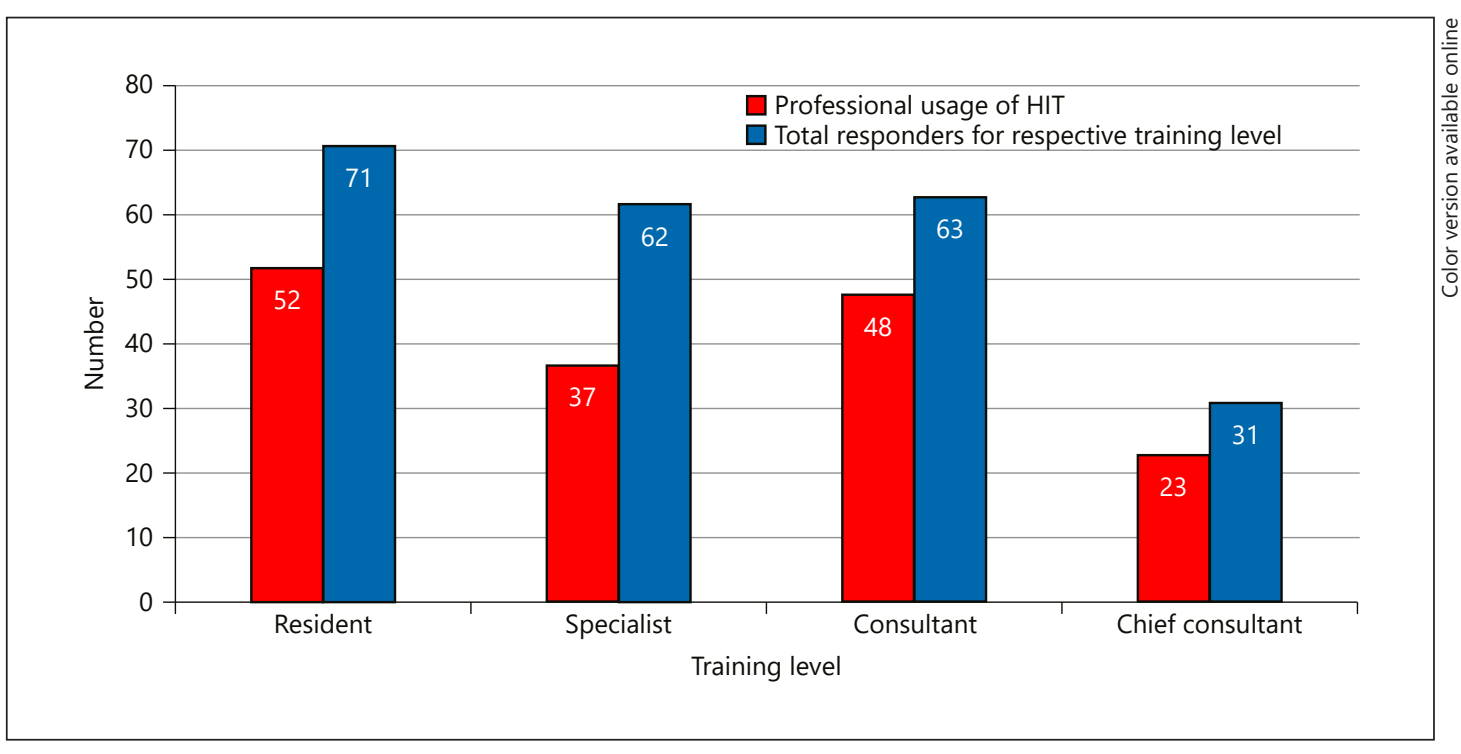

Fig. 6. Training level of healthcare professionals employing HIT at occupational level - RQ 1.

Regarding interoperability and remote data use, $69.1 \%$ responded that no patient data can be used or accessed by physicians from outside the hospital server system (Fig. 4).

As illustrated in Figure 5, 51.3\% of physicians use an electronic calendar within the hospital's computer system to schedule appointments for their patients. Of those, only $11.9 \%$ use an electronic calendar that is accessible for patients or other physicians to directly make appointments online or to engage in intraorganizational communication.

Analysis of the frequency of professional use of HIT in dependence to varying training levels of physicians yielded the following percentages: residents (doctors-in-training) $73.24 \%$, specialists (fully qualified physicians) $59.68 \%$, consultants (senior physicians) $76.19 \%$ and chief consultants (department heads and directors) $74.19 \%$. These results are depicted in Figure 6. 
Vogt et al.: Healthcare IT Utilization and Penetration among Physicians: Novel IT

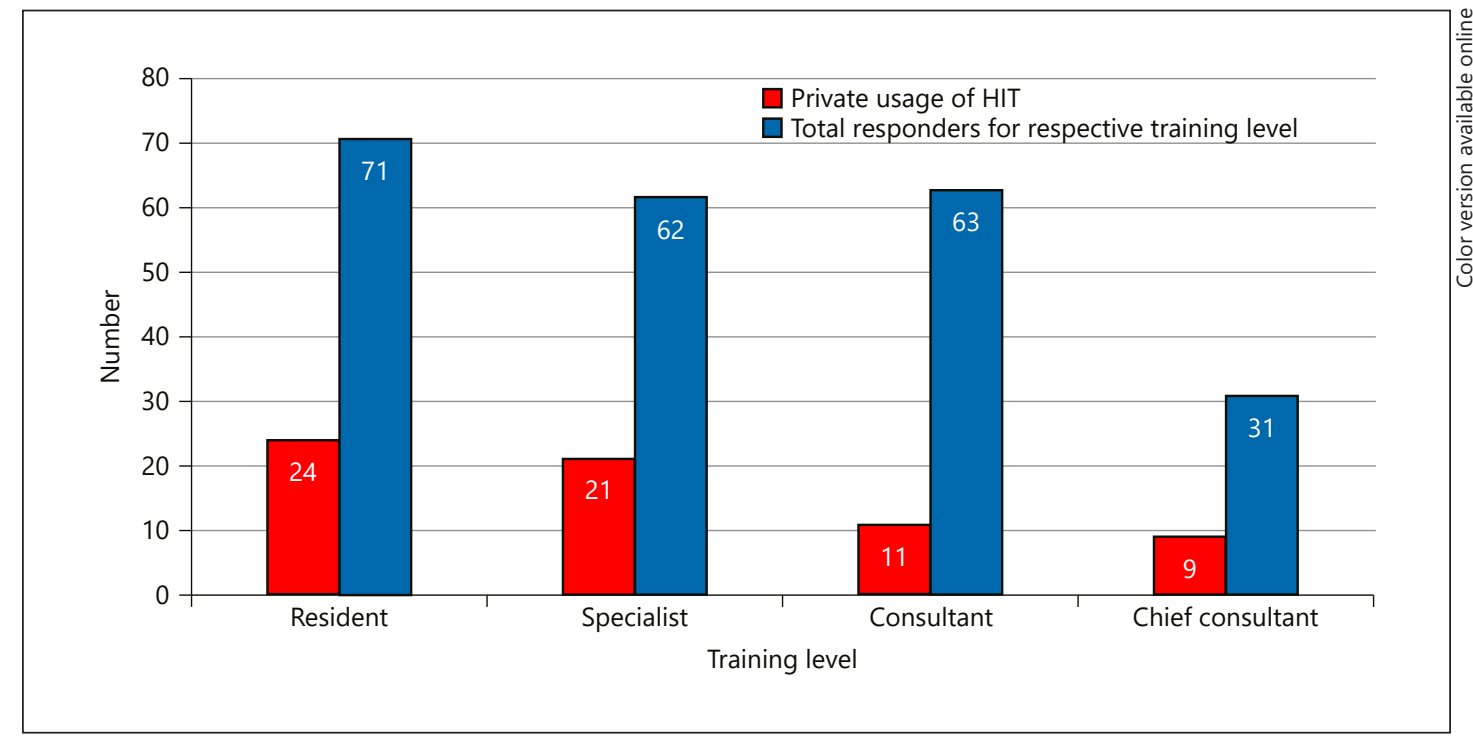

Fig. 7. Training level of healthcare professionals employing HIT at private level - RQ 1.

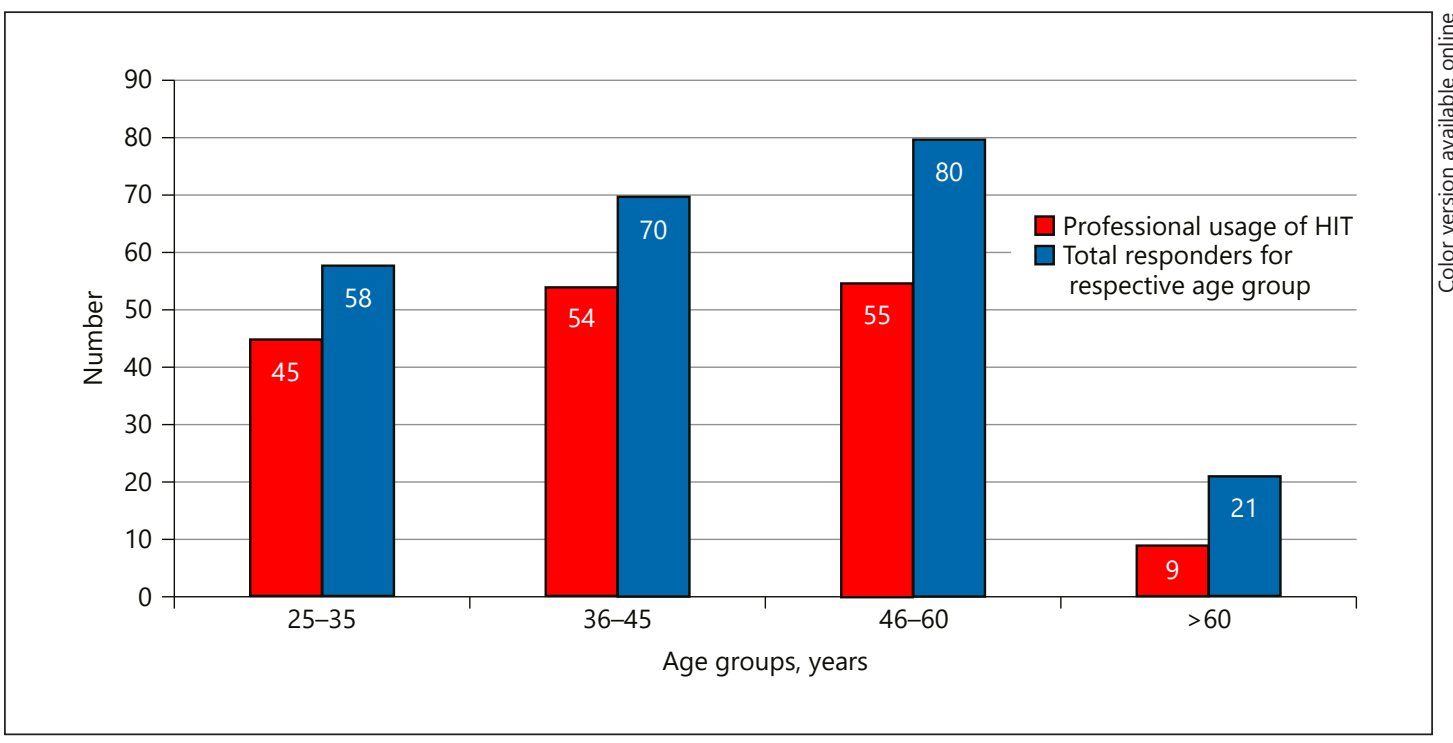

Fig. 8. Age of healthcare professionals employing HIT at occupational level - RQ 1.

This trend is reversed when it comes to private use of these applications. These are used by $33.80 \%$ of all residents, by $33.87 \%$ of specialists, by $17.46 \%$ of consultants and finally by $29.03 \%$ of chief consultants among the responding physicians. The corresponding values are shown in Figure 7.

In contrast, the analysis of age-specific groups (25-35, 36-45, 46-60 and >60 years) yields markedly negative trends with increasing age of respondents (Fig. 8). Within our data set, the average age of responders was 45 years.

Physicians of all age groups make use of HIT applications considerably less in private than in professional life, as shown in Figure 9. 
Vogt et al.: Healthcare IT Utilization and Penetration among Physicians: Novel IT Solutions in Healthcare - Use and Acceptance in Hospitals

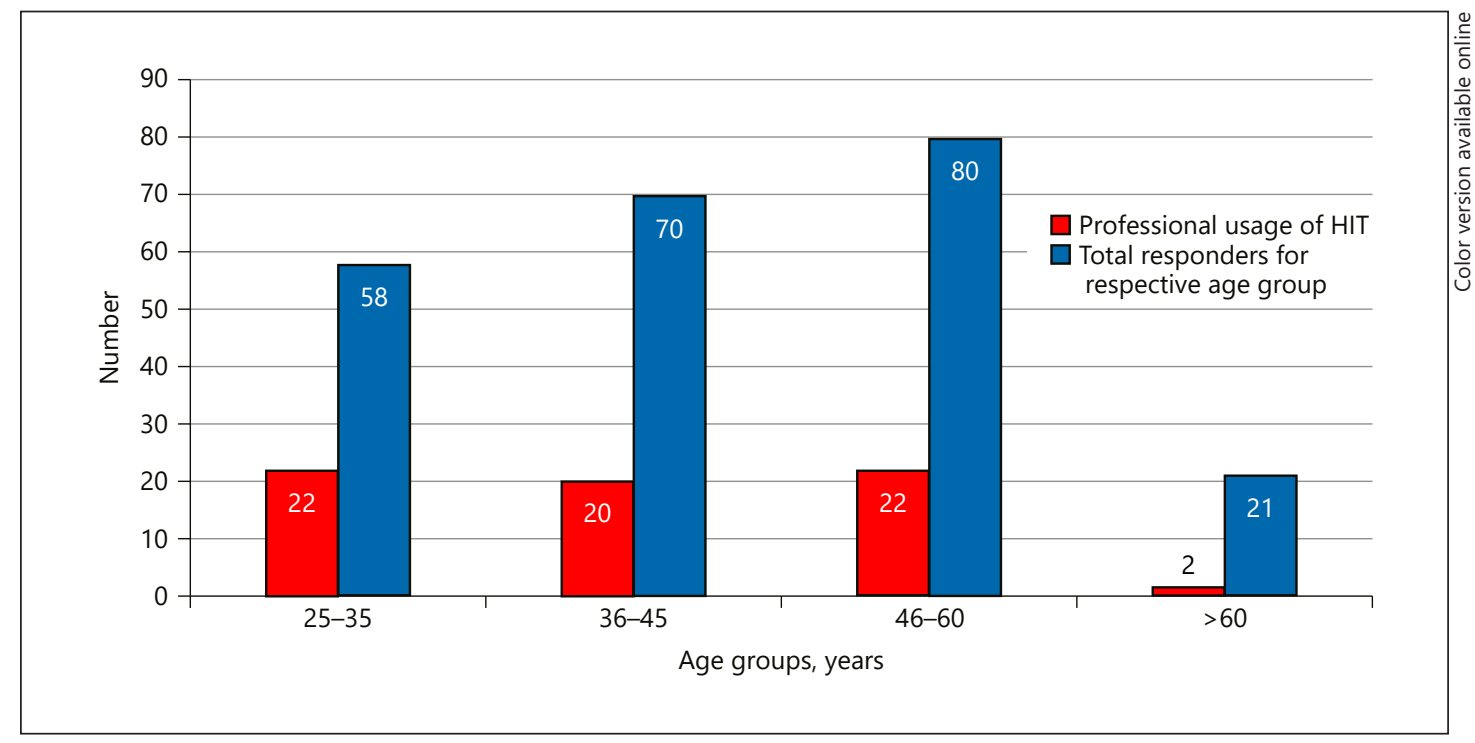

Fig. 9. Age of healthcare professionals employing HIT at private level - RQ 1.

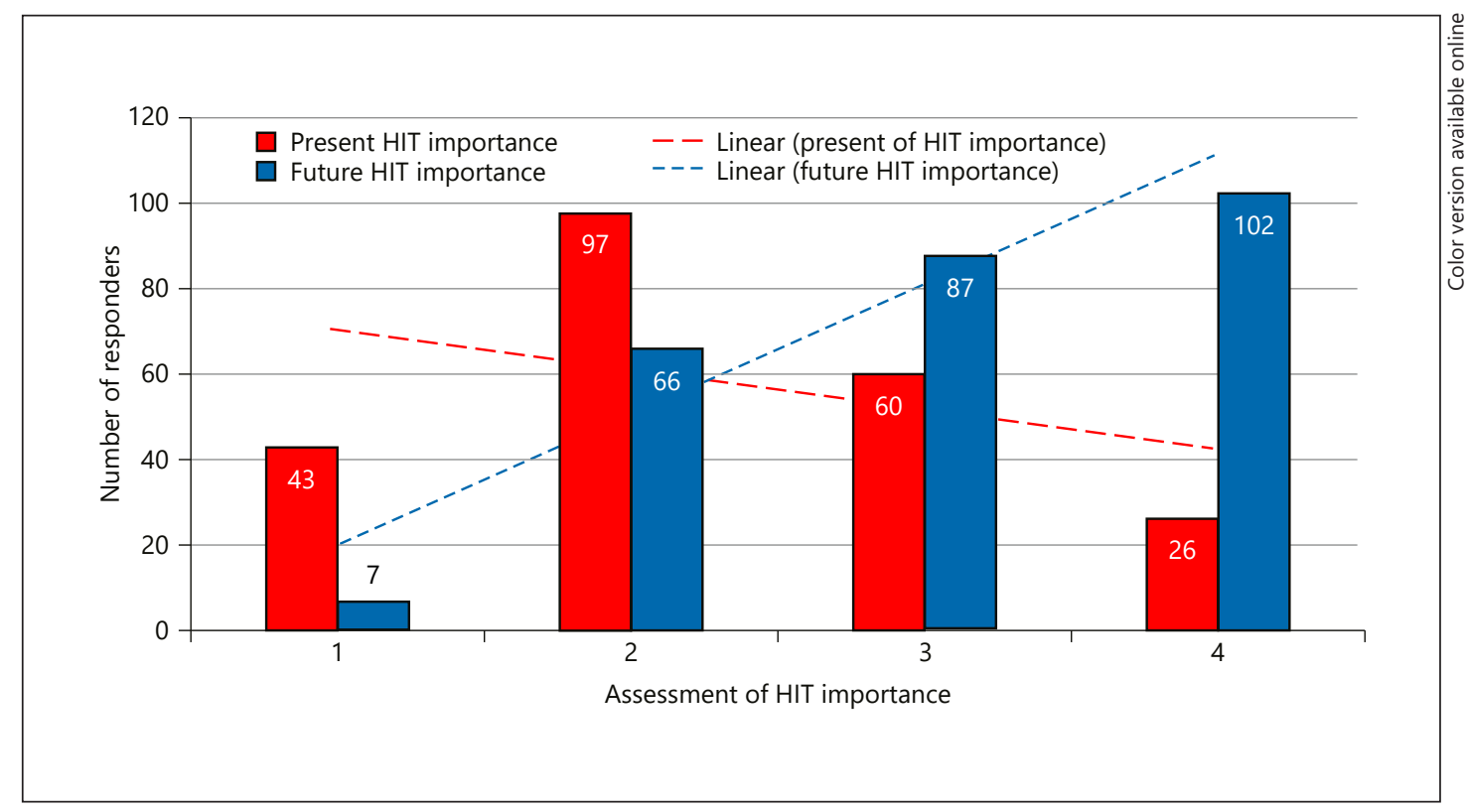

Fig. 10. Present and future assessment among healthcare professionals regarding the importance of HIT; values correspond to $1=$ unimportant, 2 = vaguely important, $3=$ important, $4=$ very important $-\mathrm{RQ} 2$ and RQ 3.

Results Regarding the Secondary Research Questions (RQ2-RQ4)

$62.3 \%$ of participating physicians believe HIT to be of no or low influence on medical treatment in general, while at the same time a strong majority believes in a future change. $82.7 \%$ believe the HIT offer to influence medical practice significantly within the next 5 years. Descriptive analysis was performed on answers to both questions, whose trend lines show that responders currently assess the importance of HIT as preponderantly moderate, but 
Vogt et al.: Healthcare IT Utilization and Penetration among Physicians: Novel IT

Solutions in Healthcare - Use and Acceptance in Hospitals

with a considerably growing impact in the future (Fig. 10, which combines the depiction of results both for RQ2 and RQ3).

Finally, the results from the open text questions, which will be presented in the last paragraphs of this section, will provide an answer to RQ4 (without graphical depiction).

Regarding the perceived economic potential of HIT, responders of the questionnaire agreed that HIT might pose an option to reduce cost burdens (i.e., $51.5 \%$ believe costs to be reduced, while $34.5 \%$ think that costs associated with HIT pose a major obstacle for its development and use). According to the respondents, expanding HIT usage can positively influence the following: increased treatment safety $(75.8 \%)$, reduction of redundancies $(68.8 \%)$ and increased data safety $(67.7 \%)$.

Detailing the latter point, questions regarding storage of personal medical data show that $58.7 \%$ trust an electronic health card or file, provided by the state. $57.4 \%$ believe their data to be secure within a hospital or with their physician. In harsh contrast, only $10.3 \%$ would rely on a cloud solution, only $4.5 \%$ on a commercial platform and only $3.1 \%$ on their insurance provider to store health data.

$75.1 \%$ of respondents expect a rise in treatment safety, $72.9 \%$ an acceleration of treatment and $65.1 \%$ more comfort for the patient. The largest development potential is expected by $68.6 \%$ in the reduction of administrative work and redundancies. $64.6 \%$ recognize a general rise of efficiency, while $46 \%$ believe in a rise in quality of treatment. On the other hand, the largest risk is suspected by $69.7 \%$ in a lack of interoperability between IT systems and lack of data security (67.5\%). More than half of the respondents (50.6\%) doubt technical feasibility in hospitals and private practice.

\section{Discussion}

With the growth of new and exciting HIT opportunities comes the daunting responsibility to design e-health tools that communicate effectively with a diverse array of healthcare consumers, providers and policy makers [20]. The growth of e-health tools has spurred an information revolution within the modern healthcare system that holds tremendous promise for enhancing the delivery of care and the promotion of health [20]. The underlying study helps in understanding the current everyday employment of HIT by physicians.

Earlier literature has defined the physician with a caring attitude as the ideal [21]. This aspect will in the near future not be fulfilled by a technological solution, partially explaining the difficulty of rapid HIT adoption.

To allow for a common discussion, the authors herewith define HIT as an open field of applications to process healthcare information with the necessity of an advantage over common data storage. HIT can allow patients to gain an overview over their health records, with the ability to share data safely with their physicians and therefore be able to access information about their health status. On the other hand, HIT should provide physicians with the relevant clinical data and draw conclusions to support them during the decision-making process and ease the communication with their colleagues and the patients.

Obstacles for the current use of HIT can be found in the following factors: (1) availability, (2) understanding, (3) reimbursability, and (4) data security issues. A growing number of patients use HIT devices, e.g. their smartphones, wearables like fitness trackers or onlinebased tools, to monitor their own health, well-being and physical conditions in case of various pathological entities, or to simply inform themselves about their treatment plan [22, 23]. Currently only $11.9 \%$ of responding physicians use an electronic calendar accessible for patients or other physicians to make direct appointments. A lack of such possibilities in today's practice becomes apparent when comparing it to service industries. HIT can improve 
Vogt et al.: Healthcare IT Utilization and Penetration among Physicians: Novel IT

Solutions in Healthcare - Use and Acceptance in Hospitals

patient safety by evaluating potential drug-drug interactions, compensating for human errors in dosing, and eliminating mistakes caused by illegible handwriting. The study reveals that age is one of the limiting factors for further HIT penetration as can be derived from Figure 8. Data security still poses a major problem for users as well as patients to overcome the hurdle [24].

Furthermore, it was observed that HIT penetration is partially dependent on both level and degree of specialization in medicine as can be derived from Figure 6. This raises the question whether certain subgroups of physicians have thus far been not addressed adequately. To match supply and demand in this sector as well as the chance for opening the big data potential leaves a large and relatively untapped potential both economically and scientifically [25-27].

The need for systematic documentation is obvious, but consumes up to $4 \mathrm{~h}(44 \%)$ of a clinical physicians' work per day [28]. This time consequently cannot be spent on direct patient contact. Adopting electronic work in daily clinic business is not the main issue of a doctor's life compared to conventional office workers. In addition, the age of employees in hospitals has continuously increased since 1993 [29]. The rate of dissatisfaction when using HIT within hospitals ranges between 45 and 80\% [30]. This survey reveals the current status and future needs as well as demand of physicians. A considerable majority of respondents expect the use and importance of IT to rise within the next years. At the same time, future expectations from and velocity of technological development in HIT are continuously rising $[26,31]$.

Two major issues need to be resolved in the upcoming years to lay the foundation for revolutionary developments: firstly, data security will have to be ensured to allow for the necessary trust, to help patients and thus users to differentiate between data collectors and data enablers. Secondly, politics need to lay the legal groundwork for successful and secure data exchange between involved parties [32]. This requirement for political commitment and a sound overall strategy to overcome barriers in the way of HIT improvement is underlined by a most recent study conducted among experts in digitalization in the German healthcare system [33]. Also, previous studies have shown that $32 \%$ of patients are willing to record medical data and share it with their insurance companies, while $39 \%$ would not be willing to do so [34]. This expresses the current lack of trust among patients.

Incentives for a more rapid deployment and use of medical and administrative applications are small; however, some projects were initiated by legislation (German eHealth act) but none of them were implemented in time. To give an example, since June 2016, the telematics infrastructure should be available for all players of the healthcare system to get information and to update patients' insurance data via a nationwide network. Furthermore, from July 2016 on, hospitals have been bound to share their electronic discharge letters with established doctors, which in fact started 1 year later. From October 2016 on, patients with more than 5 prescribed medicines should get a medication schedule in paper form by the general practitioner, but availability via the electronic health card (elektronische Gesundheitskarte) is still lacking. Also, an emergency record documentation via this electronic health card failed [35].

Overall a sign of distrust as well as lack of understanding and of interoperability were shown to limit HIT's use. Future developments will have to take physicians' understanding and demands into account to enable broad acceptance and employment of modern approaches. Further research may compare IT solutions developed with and by medical staff to others. 
Vogt et al.: Healthcare IT Utilization and Penetration among Physicians: Novel IT

Solutions in Healthcare - Use and Acceptance in Hospitals

\section{Conclusion}

This study shows that the current use of HIT today remains below expectations of its respondents on several levels. Physicians are willing and eager to use IT, as proven by their private use, but need more suitable and convenient HIT to do so on a daily professional base. From an economic point of view, advances regarding HIT might be a way to reduce costs for physicians both in clinics and private practices.

Overall, the study shows that HIT is regarded as being important and is expected to continuously grow in importance in the healthcare environment.

Further research may allow us to understand the day-to-day specific needs of physicians. Currently, IT shows a great bandwidth of solutions, answering a small range of healthcare and medical scientific questions. To match this supply with the actual demand will be key to further success and developments. Market dynamics will be unstoppable in doing so, as long as an economic bottleneck can be surpassed by additional offerings within the current legal and data security framework.

The future of HIT offers various possibilities yet involves large amounts of regulations and influencing factors. Once the legal groundwork has been laid to facilitate implementation of HIT, patients, providers and physicians may benefit largely from the digitalization of healthcare. This may foster cooperative medical-technical development and enhance collaboration and interoperability to satisfy current HIT needs. The new GDPR will introduce pseudonymizing of data and enforce explicit consent on usage of data. Citizens will have a broader set of rights to access, delete and transfer their personal data upon request. In addition general data protection regulations have been modified. While rendering data use technically easier the new regulation also comes with elevated barriers to enter the business. It remains to be seen how this will influence the citizens' and physicians' use of HIT.

Our study is limited by a relatively modest sample size. However, the 3-digit number of valid, complete responses allows for a sound statistical analysis. In addition, one prerequisite not taken into account is the level of digital literacy of the participating physicians. Further research may elaborate in more detail on this and include physicians from other geographical backgrounds to facilitate the understanding of HIT employment on a global scale.

\section{Acknowledgments}

This survey was part of the master's thesis of the first author (F.V.) at the postgraduate part-time executive degree course for the Master of Health Business Administration (MHBA) at Friedrich Alexander University Erlangen-Nuremberg.

\section{Statement of Ethics}

No patients or animals were treated or harmed or interviewed; no immediate medical treatment consequences will be drawn from this analysis.

\section{Disclosure Statement}

The authors declare that they have no conflicts of interest. 


\section{Appendix}

Questionnaire (translated version)

\begin{tabular}{|c|c|}
\hline 1 & $\begin{array}{l}\text { How often do you make use of medical online offerings (e.g., Red List, Pubmed, UptoDate, } \\
\text { Cochrane Library, Google Scholar etc.) in your professional life? } \\
\text { Likert scale: } 1 \text { = never; } 2 \text { = rarely; } 3 \text { = often; } 4 \text { = regularly }\end{array}$ \\
\hline 2 & $\begin{array}{l}\text { How often do you make use of medical online offerings (e.g., Red List, Pubmed, UptoDate, } \\
\text { Cochrane Library, Google Scholar etc.) in your private life? } \\
\text { Likert scale: } 1 \text { = never; } 2 \text { = rarely; } 3 \text { = often; } 4 \text { = regularly }\end{array}$ \\
\hline 3 & $\begin{array}{l}\text { Which of the following mobile devices do you make use of in your clinical routine, e.g. for ward } \\
\text { rounds/patient contact? } \\
\text { Multiple choice: A = private device; } \mathrm{B}=\text { device provided by the clinic; } \mathrm{C}=\text { both; } \mathrm{D}=\mathrm{I} \text { do not use } \\
\text { mobile devices }\end{array}$ \\
\hline 4 & $\begin{array}{l}\text { Do you have remote online access to your facility's hospital information system? } \\
\text { Yes/No: A = yes; B = no }\end{array}$ \\
\hline 5 & $\begin{array}{l}\text { Do you employ an electronic calendar for organizing patient appointments? } \\
\text { Yes/No: A = yes; B = no }\end{array}$ \\
\hline 6 & $\begin{array}{l}\text { Do patients or referring physicians - also clinic-internally - have the possibility to directly access } \\
\text { this electronic calendar online? } \\
\text { Yes/No: A = yes; B = no }\end{array}$ \\
\hline 7 & $\begin{array}{l}\text { Do you use an online platform or cloud solution to store your personal health data? } \\
\text { Yes/No: A = yes; B = no }\end{array}$ \\
\hline 8 & $\begin{array}{l}\text { Do your patients use an online platform or cloud solution to save their personal health data? } \\
\text { Likert scale: } 1 \text { = no one; } 2 \text { = only a few; } 3=\text { many; } 4=\text { most of them }\end{array}$ \\
\hline 9 & $\begin{array}{l}\text { As a physician, do you download clinical data of your patients from other medical facilities from } \\
\text { outside your organization? } \\
\text { Likert scale: } 1 \text { = never; } 2 \text { = rarely; } 3 \text { = often; } 4 \text { = regularly }\end{array}$ \\
\hline 10 & $\begin{array}{l}\text { How do you assess the current importance of healthcare IT services in medicine in general? } \\
\text { Likert scale: } 1 \text { = unimportant; } 2 \text { = vaguely important; } 3 \text { = important; } 4 \text { = very important }\end{array}$ \\
\hline 11 & $\begin{array}{l}\text { How do you assess the future importance of healthcare IT services in medical action in general? } \\
\text { Likert scale: } 1 \text { = unimportant; } 2 \text { = vaguely important; } 3 \text { = important; } 4 \text { = very important }\end{array}$ \\
\hline $\begin{array}{l}\text { Ope } \\
12\end{array}$ & $\begin{array}{l}\text { tions } \\
\text { What can a well-implemented healthcare IT achieve for your patients in your opinion? }\end{array}$ \\
\hline 13 & Which development potentials and chances do you see in healthcare IT? \\
\hline 14 & Where do you see the greatest risks and disadvantages of healthcare IT? \\
\hline 15 & $\begin{array}{l}\text { How and where should personal health data be stored and saved in your opinion? } \\
\text { Multiple choice: } A=\text { electronic health card or electronic health file; } B=\text { medical facility (e.g., GP or } \\
\text { hospital); } C \text { = insurance; D = private cloud storage; } E \text { = commercial supplier }\end{array}$ \\
\hline 16 & $\begin{array}{l}\text { Personal details: Gender } \\
\text { Multiple choice: } \mathrm{A} \text { = female; } \mathrm{B}=\text { male }\end{array}$ \\
\hline 17 & $\begin{array}{l}\text { Personal details: Training level } \\
\text { Multiple choice: } \mathrm{A}=\text { resident; } \mathrm{B}=\text { specialist; } \mathrm{C}=\text { consultant; } \mathrm{D}=\text { chief consultant }\end{array}$ \\
\hline 18 & $\begin{array}{l}\text { Personal details: Medical specialization } \\
\text { Multiple choice: } \mathrm{A}=\text { anesthesia/emergency medicine; } \mathrm{B}=\text { cardiology; } \mathrm{C}=\text { dermatology; } \mathrm{D}=\text { ear, } \\
\text { nose, throat; } \mathrm{E}=\text { general medicine; } \mathrm{F}=\text { general surgery; } \mathrm{G}=\text { gynecology; } \mathrm{H}=\text { heart surgery; } \\
\mathrm{I}=\text { internal medicine; } \mathrm{J}=\text { microbiology/hygiene; } \mathrm{K}=\text { nephrology; } \mathrm{L}=\text { no patient-related work; } \\
\mathrm{M}=\text { oncology; } \mathrm{N}=\text { orthopedics/trauma surgery; } \mathrm{O}=\text { pathology/histology; } \mathrm{Q}=\text { psychiatry and } \\
\text { psychotherapy; } \mathrm{R}=\text { radiology; } \mathrm{S}=\text { vascular surgery }\end{array}$ \\
\hline 19 & $\begin{array}{l}\text { Personal details: Type of employment } \\
\text { Multiple choice: } \mathrm{A}=\text { clinic; } \mathrm{B}=\text { doctor in private practice }\end{array}$ \\
\hline 20 & $\begin{array}{l}\text { Personal details: Age } \\
\text { Multiple choice: } \mathrm{A}=25-35 ; \mathrm{B}=36-45 ; \mathrm{C}=46-60 ; \mathrm{D}=\text { older than } 60\end{array}$ \\
\hline
\end{tabular}




\begin{tabular}{l|l}
\hline Eur Surg Res 2018;59:100-113 \\
\hline DOI: 10.1159/000490241 & $\begin{array}{l}\text { @ 2 2018 S. Karger AG, Basel } \\
\text { www.karger.com/esr }\end{array}$ \\
\hline
\end{tabular}

Vogt et al.: Healthcare IT Utilization and Penetration among Physicians: Novel IT

Solutions in Healthcare - Use and Acceptance in Hospitals

\section{References}

1 Martikainen S, Viitanen J, Korpela M, Laaveri T: Physicians' experiences of participation in healthcare IT development in Finland: willing but not able. Int J Med Inform 2012;81:98-113.

2 Nguyen HH, Silva JNA: Use of smartphone technology in cardiology. Trends Cardiovasc Med 2016;26:376-386.

3 McBain H, Shipley M, Newman S: The impact of self-monitoring in chronic illness on healthcare utilisation: a systematic review of reviews. BMC Health Serv Res 2015;15:1-10.

4 Zuidema RM, van Gaal BG, van Dulmen S, Repping-Wuts H, Schoonhoven L: An online tailored self-management program for patients with rheumatoid arthritis: a developmental study. JMIR Res Prot 2015;4:e140.

5 Lai Y-H: A network meta-analysis on the effects of information technology application on preoperative knowledge of patients. Int J Emerg Trends Technol Comput Sci 2014;3:326-332.

6 Alpert JM, Krist AH, Aycock RA, Kreps GL: Applying multiple methods to comprehensively evaluate a patient portal's effectiveness to convey information to patients. J Med Internet Res 2016;18:e112.

7 Kritz M, Gschwandtner M, Stefanov V, Hanbury A, Samwald M: Utilization and perceived problems of online medical resources and search tools among different groups of European physicians. J Med Internet Res 2013; 15:e122.

8 Luo W, Najdawi M: Trust-building measures: a review of consumer health portals. Commun ACM 2004;47:108113.

9 US Department of Health and Human Services: Health information technology: what is health IT? Washington, US Department of Health and Human Services, 2015,

10 DeLuca JM, Enmark R: E-health: the changing model of healthcare. Front Health Serv Manage 2000;17:3-15.

11 Wiley-Patton S, Malloy A: Understanding healthcare professionals' adoption and use of IT. AMCIS 2004 Proceedings, New York, 2004, paper 27.

12 Shekelle PG, Morton SC, Keeler EB: Costs and benefits of health information technology. Evidence report/technology assessment 2006, pp 1-71.

13 Hesse BW, Nelson DE, Kreps GL, et al: Trust and sources of health information: the impact of the internet and its implications for health care providers: findings from the first health information national trends survey. Arch Intern Med 2005;165:2618-2624.

14 Chau PY, Hu PJ-H: Investigating healthcare professionals' decisions to accept telemedicine technology: an empirical test of competing theories. Inform Manage 2002;39:297-311.

15 Norris AC, Stockdale RS, Sharma S: A strategic approach to m-health. Health Inform J 2009;15:244-253.

16 Gschwind YJ, Eichberg S, Ejupi A, de Rosario H, Kroll M, Marston HR, Drobics M, Annegarn J, Wieching R, Lord SR, Aal K, Vaziri D, Woodbury A, Fink D, Delbaere K: ICT-based system to predict and prevent falls (iStoppFalls): results from an international multicenter randomized controlled trial. Eur Rev Aging Phys Activity 2015;12:10.

17 Marston HR, Woodbury A, Gschwind YJ, Kroll M, Fink D, Eichberg S, Kreiner K, Ejupi A, Annegarn J, de Rosario H, Wienholtz A, Wieching R, Delbaere K: The design of a purpose-built exergame for fall prediction and prevention for older people. Eur Rev Aging Phys Activity 2015;12:1-12.

18 Lluch M: Incentives for telehealthcare deployment that support integrated care: a comparative analysis across eight European countries. Int J Integr Care 2013;13:e042.

19 Müschenich M: Wir Ärzte haben die Pflicht, IT in die Therapie zu integrieren. MMW Fortschr Med 2015;157:17.

20 Kreps GL, Neuhauser L: Editors' introduction: ehealth and the delivery of health care. J Comput Med Commun 2010;15:364-366.

21 Emanuel EJ, Emanuel LL: Four models of the physician-patient relationship. JAMA 1992;267:2221-2226.

22 Free C, Phillips G, Galli L, Watson L, Felix L, Edwards P, Patel V, Haines A: The effectiveness of mobile-health technology-based health behaviour change or disease management interventions for health care consumers: a systematic review. PLoS Med 2013;10:e1001362.

23 Nielsen JA, Mengiste SA: Analysing the diffusion and adoption of mobile IT across social worlds. Health Inform J 2014;20:87-103.

24 Bengtsson S, Solheim B: Enforcement of data protection, privacy and security in medical informatics. Medinfo 1992;92:6-10.

25 Murdoch TB, Detsky AS: The inevitable application of big data to health care. JAMA 2013;309:1351-1352.

26 Raghupathi W, Raghupathi V: Big data analytics in healthcare: promise and potential. Health Inform Sci Syst 2014;2:3.

27 Sun J, Reddy CK: Big data analytics for healthcare. Proceedings of the 19th ACM SIGKDD International Conference on Knowledge Discovery and Data Mining, Chicago, 2013, pp 1525-1525.

28 Wise PB: Value of health IT: HIMSS health information technology value model. Med Inform 2016;1.

29 Kopetsch T: Dem deutschen Gesundheitswesen gehen die Ärzte aus! Studie zur Altersstruktur- und Arztzahlentwicklung. Berlin, Bundesärztekammer, 2010, p 146.

30 Bundesverband Gesundheits-IT eV: bvitg eV veröffentlicht Branchenbarometer 2012.

31 Ball MJ, Lillis J: E-health: transforming the physician/patient relationship. Int J Med Inform 2001;61:1-10.

32 HEALTH-CARE-COM GmbH: Trend Guide Gesundheits-IT - Innovationen und Entwicklungen 2015.

33 Nohl-Deryk P, Brinkmann JK, Gerlach FM, Schreyogg J, Achelrod D: Barriers to digitalisation of healthcare in Germany: a survey of experts (in German). Gesundheitswesen 2018, Epub ahead of print.

34 YouGovReports: Quantified Health - Die vernetzte Gesundheit: Chancen und Barrieren. 2015.

35 Aerzteblatt.de: E-Health-Gesetz: Die wichtigsten Inhalte des Referentenentwurfs, 2015. 